\title{
'Good-genes' and 'compatible-genes' effects in an Alpine whitefish and the information content of breeding tubercles over the course of the spawning season
}

\author{
Claus Wedekind · Guillaume Evanno • \\ Davnah Urbach · Alain Jacob · Rudolf Müller
}

Received: 22 January 2007/ Accepted: 11 June 2007 / Published online: 13 July 2007

(C) Springer Science+Business Media B.V. 2007

\begin{abstract}
Some models of sexual selection predict that individuals vary in their genetic quality and reveal some of this variation in their secondary sexual characteristics. Alpine whitefish (Coregonus sp.) develop breeding tubercles shortly before their spawning season. These tubercles are epidermal structures that are distributed regularly along the body sides of both males and females. There is still much unexplained variation in the size of breeding tubercles within both sexes and with much overlap between the sexes. It has been suggested that breeding tubercles function to maintain body contact between the mating partners during spawning, act as weapons for defence of spawning territories, or are sexual signals that reveal aspects of genetic quality. We took two samples of whitefish from their spawning place, one at the beginning and one around the peak of spawning season. We found that females have on average smaller breeding tubercles than males, and that
\end{abstract}

\author{
C. Wedekind $(\bowtie) \cdot$ G. Evanno $\cdot$ D. Urbach . \\ A. Jacob \\ Department of Ecology and Evolution, Biophore, University \\ of Lausanne, Lausanne 1015, Switzerland \\ e-mail: claus.wedekind@unil.ch \\ G. Evanno \\ e-mail: guillaume.evanno@unil.ch \\ D. Urbach \\ e-mail: davnah.urbach@unil.ch \\ A. Jacob \\ e-mail: alain.jacob@unil.ch \\ C. Wedekind · R. Müller \\ Eawag, Swiss Federal Institute of Aquatic Science and \\ Technology, Kastanienbaum 6047, Switzerland \\ C. Wedekind \\ e-mail: claus.wedekind@unil.ch \\ R. Müller \\ e-mail: rudolf.mueller@eawag.ch
}

tubercle size partly reveals the stage of gonad maturation. Two independent full-factorial breeding experiments revealed that embryo mortality was significantly influenced by male and female effects. This finding demonstrates that the males differed in their genetic quality (because offspring get nothing but genes from their fathers). Tubercle size was negatively linked to some aspects of embryo mortality in the first breeding experiment but not significantly so in the second. This lack of consistency adds to inconsistent results that were reported before and suggests that (i) some aspects of genetic quality are not revealed in breeding tubercles while others are, or (ii) individuals vary in their signaling strategies and the information content of breeding tubercles is not always reliable. Moreover, the fact that female whitefish have breeding tubercles of significant size while males seem to have few reasons to be choosy suggests that the tubercles might also serve some functions that are not linked to sexual signaling.

Keywords Good-genes sexual selection - Secondary sexual characters - Breeding tubercles - Perl organ · Signaling $\cdot$ Contact organ $\cdot$ Embryo viability $\cdot$ Salmonids

\section{Introduction}

Females are usually more likely to mate with males that are attractive or superior competitors in intra-sexual competition. This may be so if males differ in genetic quality, and more attractive or more dominant males may provide genetic benefits for the offspring (Andersson 1994; Qvarnstrom and Forsgren 1998; Wedekind 2002; Neff and Pitcher 2005). Empirical tests of this so-called 'good genes' hypothesis of sexual selection usually suffer from the problem that the predicted effects could be confounded with non-genetic effects, e.g., the amount of care a male is 
able or willing to provide (Milinski and Bakker 1990; Hill 1991; Iyengar and Eisner 1999), or differences in the number of eggs or egg quality that could be conditionally biased by the female in response to the perceived quality of her mate (Petrie and Williams 1993; Wedekind et al. 1998; Johnsen et al. 2005; Gilbert et al. 2006). Therefore, the ideal model species to test for genetic effects of sexual selection is a species with no paternal care, external fertilization, and large family size. This is the case in many frogs (Welch et al. 1998; Welch 2003) and fish (Wedekind et al. 2001a; Kortet et al. 2004a; Rudolfsen et al. 2005; Pitcher and Neff 2006a; Bang et al. 2006). In salmonids like whitefish, males provide only genes to their offspring, individual females can produce thousands of eggs for one breeding season, and eggs can be fertilized and reared in the laboratory under very controlled conditions. We therefore use salmonid fish as a model to test whether variation in genetic quality could play a role in sexual selection.

'Genetic quality' is, in the context of sexual selection, an umbrella term. It includes 'good genes' and 'compatible genes' (Neff and Pitcher 2005). 'Good genes' are alleles that increase fitness directly and, in principle, independently of the rest of the genome. If variation in such loci exists within a population, i.e., when there is variation in fitness that can be linked to such loci, population studies will show additive genetic variance for viability, and populations are expected to evolve in response to directed selection. 'Compatible genes' are defined as alleles that increase fitness only when in combination with other alleles, i.e., only when in a specific genotype. Such fitness effects can be due to epistasis, i.e., to interactions with alleles on other loci, or due to any sort of heterozygote advantage (e.g., overdominance) or disadvantage. 'Compatible-gene' effects will be revealed in significant nonadditive genetic variance for viability: some male-female combinations will then have a higher fitness than other combinations, regardless of possible 'good-genes' effects.

One of the key predictions of most 'good-genes' models is that female choice is based on morphological or behavioural male characteristics that reveal superior genetic quality. In the case of salmonids, males differ in age and size, i.e., in characteristics that are usually linked to dominance at the spawning place (Fleming and Gross 1994; Quinn and Foote 1994; Fleming 1998; Garant et al. 2001; Largiadèr et al. 2001; Garant et al. 2003; Weir et al. 2004; Dickerson et al. 2005; Jacob et al. submitted). However, neither male age nor size seems to be linked to genetic quality in at least three different salmonid species and when tested within blocks of experimental breeding and rearing of embryos (Coregonus zugensis Nüsslin: (Rudolfsen et al, in press); C. fatioi Kotellat: (Urbach et al. in press); Salmo trutta L.: (Jacob et al. submitted)).
If age, size, and dominance do not reveal genetic quality, then maybe secondary sexual characters do. At spawning season, mature Alpine whitefish (Coregonus sp.) have breeding tubercles (sometimes also called: nuptial tubercles or perl organs). Breeding tubercles are small and mostly coniform, millet-grain sized, milky to colourless epidermal structures. They are found in at least 15 teleost families in four orders (Salmoniformes, Gonorhynchiformes, Cypriniformes, and Perciformes), and similar structures are found in several other orders (Wiley and Collette, 1970). The development of breeding tubercles is induced by various steroids shortly before the spawning season (Wiley and Collette, 1970). The tubercles fall off shortly afterwards. In roach (Rutilus rutilus L.) where only males and some old females develop breeding tubercles, tubercle size is linked to the concentrations of circulating testosterone and 11-ketotestosterone during breeding season (Kortet et al. 2003). In the case of coregonids, both males and females develop breeding tubercles that are regularily distributed along both body sides and that can vary enormously in size between individuals (Wedekind et al. 2001a).

The breeding system of whitefish is not fully understood yet (Rudolfsen et al. submitted), but the functional significance of breeding tubercles is not even clear in species where we know more about the reproductive biology as, for example, in roach (Rutilus rutilus L., see references below). It has been suggested that breeding tubercles facilitate the maintenance of body contact between the mating partners during spawning (Wiley and Collette 1970), act as weapons for the defense of spawning territories (Wiley and Collette 1970; Wedekind 1996; Kortet et al. 2004b), or are sexual signals that reveal good genes (Wedekind 1992; Taskinen and Kortet 2002; Kortet et al. 2004b). However, given the usually small size of breeding tubercles and the material they are made of (Wiley and Collette 1970), it is not clear yet whether they could act as handicapping signals in the sense of Zahavi (1975), i.e., like some secondary sexual characteristics of, for example, members of the pheasant family (see also Discussion).

In various cyprinids and coregonids, i.e., in all iteroparous group spawners with external fertilization that have been tested so far, the size of breeding tubercles is positively linked to male dominance, size, or age (Wedekind 1992; Müller and Ward 1995; Kortet and Taskinen 2004; Kortet et al. 2004b; Ottova et al. 2005; Rudolfsen et al. submitted), but not significantly to condition factor (Wedekind 1992; Kortet and Taskinen 2004; Wedekind and Müller 2004; Ottova et al. 2005), sperm velocity (Kortet et al. 2004b; Rudolfsen et al. submitted) or milt potency (Wedekind et al. 2007). Breeding tubercles are often linked to pathogen load, i.e., potentially revealing good general health and vigour (Wedekind 1992; Müller 
and Ward 1995; Kortet et al. 2003; Kortet and Taskinen 2004; Kortet et al. 2004a; Ottova et al. 2005). However, while several of these correlations are negative as predicted from Hamilton and Zuk (1982), some are positive (Müller and Ward 1995; Kortet et al. 2003; one of three pathogens in Kortet and Taskinen 2004), possibly revealing confounding effects of fish age and parasite accumulation especially in the case of long-lived helminths. First studies that included genetic aspects produced mixed outcomes, too. Müller and Ward (1995) found a negative correlation between tubercle size and overall heterozygosity. The latter is often considered as linked to superior genetic quality (Brown 1997). Wedekind et al. (2001a) found a weak positive correlation between embryo viability and the tubercle size of their fathers, but not of their mothers (see also Wedekind and Müller 2004). Kortet et al. (2004 a) found that tubercle size was negatively linked to male pathogen load, but their breeding experiment did not reveal any significant links between tubercle size and offspring viability. Hence, further studies are necessary to clarify whether breeding tubercles are signals that indeed reveal good genes.

From Bateman's principle (Andersson 1994) we predict that, in the case of group spawners with no paternal care, females are more choosy than males because the latter contribute only genes to the common offspring. If breeding tubercles are sexual signals, we may therefore predict males to have on average larger tubercles than females. Indeed, in most cyprinids the females do not develop any breeding tubercles at all, or few small ones, usually in very old individuals only (Wiley and Collette 1970). In Alpine whitefish, however, the size of male and female tubercles varies enormously and overlap between the sexes, i.e., it is not yet clear whether breeding tubercles are sexually dimorphic in this group of fish. We can see no reason why female whitefish should be ornamented as a result of sexual selection by males (no parental care, no obvious restriction to access to mating partners or sperm). However, the socalled 'genetic correlation hypothesis' (Amundsen 2000) suggests that female ornaments can be due to a nonadaptive genetic correlation that is a consequence of sexual selection on males. Alternatively, female tubercles could be non-ornamenting traits.

Here, we first test whether male and female breeding tubercles differ when potentially confounding factors like age, size, and possible sex-specific differences in the timing of maturation are taken into account. We then test whether males differ in their genetic quality and whether early or late embryo mortality could be predicted from the size of the breeding tubercles of the parents. We also provide quantitative estimates of the additive genetic variance, non-additive genetic variance, and maternal effects variance in various aspects of offspring survival in the laboratory, i.e., of potentially important fitness measures.

\section{Methods}

We took random samples from two large fishermen catches of small-type Alpine whitefish (C. zugensis). The fish were caught at about the same spawning place and on two different days during the breeding season in Lake Lucerne (central Switzerland). The first sample of in total 121 individuals was taken around the start of the breeding season (Nov 20th). The fish were caught in gill nets of two different mesh sizes that had been set in the evening before at the spawning place in about $25 \mathrm{~m}$ depth and lifted in the morning. The sample was immediately transported alive to the laboratory where we classified the males and females into those that appeared to be ready to spawn ("mature", "spawners") and those of which no milt or ripe eggs could yet be stripped ("not yet mature", "pre-spawners").

Milt was stripped from an arbitrary sample of ten male spawners by applying gentle bilateral abdominal pressure. This was done after carefully drying the genital pore to avoid accidential activation of the sperm. Until further use, the milt was kept in a closed Petri dish at low temperature (about $5^{\circ} \mathrm{C}$ ) for a maximum of $1 \mathrm{~h}$. We then stripped the eggs of two mature females, distributed these eggs about equally to ten Petri dishes each, and added to each egg batch $10 \mu \mathrm{l}$ of milt for in vitro fertilizations. The combination of milt and eggs was done in a full-factorial design, i.e., each male was crossed with each female to produce in total 20 sibships ("North Carolina II design", Lynch and Walsh 1996). Few $\mathrm{ml}$ of water were added to each Petri dish to activate the sperm, then each dish was moved gently in circles for about five seconds. About two minutes later, the Petri dishes were filled up to $50 \mathrm{ml}$ and then left undisturbed for an hour to allow for egg hardening. The water that we used here and subsequently to incubate the eggs was sand-filtered lake water that had been aerated and temperated (see Wedekind et al. (2001b) for a more detailed description of the methods). Later egg counts revealed that the milt/egg ratios we had used resulted in spermatozoa : egg ratios of at least $1.7 \times 10^{5}$, assuming 8 $\times 10^{9}$ spermatozoa/ml milt (Ciereszko and Dabrowski 1993), i.e., sperm-to-egg ratios were well above the density of about 0.3 to $0.5 \times 10^{5}$ that has been found to be necessary to secure fertilization (Rinchard et al. 2005). One day after fertilization, each batch was washed and distributed to two new Petri dishes. This resulted in 40 Petri dishes that contained on average $80.4 \mathrm{eggs} \pm 3.3$ (s.e.). The dishes were incubated without further water exchange in a climate chamber at constant $6^{\circ} \mathrm{C}$ for 31 days. Dead or nonfertilized eggs were removed on days 8 and 15 after 
fertilization and summarized as "early mortality". Embryo mortality during the time between day 15 and day 31 was recorded as "late mortality".

From previous own observations we expected the spawning season to last about three to 4 weeks. The second sample was therefore taken 9 days after the first sample, i.e., shortly before or at the peak of the spawning season, at about the same spawning place. We arbitrary selected eight mature females and eight mature males, stripped them, and used their gametes in a full-factorial breeding experiment as described above. One female turned out to have only few eggs and was therefore omitted from further analyses. Each batch of eggs was fertilized with $10 \mu \mathrm{l}$ milt each (spermatozoa : egg ratios of at least $1.8 \times 10^{5}$ ) and distributed to 2 new Petri dishes each. This resulted in 112 Petri dishes that contained on average 102.9 eggs \pm 2.3 (s.e.) and that were treated like those of the first sample. On day 31 after fertilization, all eggs of both experiments were pooled and further incubated under usual hatchery conditions for another study (Wedekind and Müller unpublished).

We determined body length, body weight, and age by counting the annual rings on scales sampled below the dorsal fin near the lateral line. Gonad maturation stage was determined by dissection and after Heincke and Maier (FAO 1965). We summarized these stages to "mature" when milt and eggs could easily be stripped or all eggs had already been spawned, and "not yet mature" for all others. We used the fresh weight of the dissected gonads to calculate the gonadosomatic index GSI = gonad weight/total body weight. Plaster casts were taken from all breeders and an arbitrary sample of further 65 males and females. This sample was not significantly different from the rest of the sample in weight, length, age, gender, liver weight, gonal weight, or gonad maturation stage ( $P$ always $>0.13$ ). The plaster casts were meant to be used to measure the height of the 16 largest tubercles per fish that could be found near the lateral line above the anal fin or below the dorsal fin (depending on plaster cast quality). These measurements could be taken for all spawners used for breeding. It turned out, however, that many of the other casts of the first sample were of too low quality to reliably determine tubercle size with the equipment we had used in Wedekind et al. (2001a), i.e., only about half of the casts could be used for quantitative measurements. We therefore used all casts to categorize the average tubercle size in the categories $0-5$ and used the 39 casts for which we had quantitative measurements to describe the six categories: 0 (no tubercles), 1 (very weak), 2 (weak, mean tubercle height $\mathrm{h}=36.4 \mu \mathrm{m} \pm 16.5 \quad \mathrm{SE}), \quad 3 \quad(\mathrm{~h}=96.1 \mu \mathrm{m} \quad \pm 18.4), \quad 4$ $(\mathrm{h}=125.5 \mu \mathrm{m} \pm 9.5)$, and $5(\mathrm{~h}=195.5 \mu \mathrm{m} \pm 10.0)$. All plaster casts of the second sample were of sufficient quality to allow for size measurements to the nearest $\mu \mathrm{m}$ of 16 tubercles per fish (methods in Wedekind et al. 2001a).

\section{Results}

First sample taken at beginning of the spawning season

In the catch the sex ratio was about equal ( 65 males and 58 females, test against 50:50, $\left.\chi^{2}=0.2, P=0.65\right)$. The age distribution was: $74 \times 2+$ (i.e., between 2 and 3 years old), $44 \times 3+$, and $3 \times 4+$. We grouped the classes $3+$ and $4+$ to "old" to allow for frequency analyses. All males and females (except one) had fully developed gonads. Females tended to be larger $(t=1.8, P=0.07)$ and were heavier $(t=3.3, P=$ $0.001)$ and older $\left(\chi^{2}=4.0, P=0.047\right)$ than the males.

Mean gonado-somatic index (GSI) of females was $17.7 \% \pm 3.9$ (s.e.) and reached up to $23.9 \%$, while the mean GSI of males was $3.2 \% \pm 0.1$ (s.e.) and reached a maximum of $4.6 \%$. Macroscopic inspection of the gonads suggested that all pre-spawners would have been ready to spawn within the next few days. The average stage of maturity was gender-specific: males were more likely to be mature at that early stage of the spawning season than females (29 males versus 12 females, $\chi^{2}=8.9, P=0.003$ ). However, two females had already spawned, i.e., the spawning season had started.

The size of breeding tubercles was not significantly linked to body size at the beginning of the spawning season ( $r=0.09, P=0.43$; males only: $r=0.25, P=0.10$; females only: $r=0.19, P=0.26$ ). To test for gender and maturation effects on the size of breeding tubercles, the factors gender and stage of maturation need to be simultaneously included in a two-factor model (because the frequency of mature females is lower than the one of mature males, see above). The breeding tubercles of females turned out to be on average smaller than those of males $(t=3.6, P<0.001)$. Figure 1 gives the size of the breeding tubercles of the mature females and mature males only $(n=28)$. Spawners had on average larger breeding tubercles than pre-spawners ( $t=4.2, P<0.001$, see also Fig. 2). This was true both for males $(t=2.1, P=0.04)$ and females $(t=3.5, P=0.03)$. There was no significant interaction between gender and maturity on the size of breeding tubercles $(t=1.2, P=$ $0.25)$. The gonadosomatic index was positively linked to tubercle size in males $(r=0.40, P=0.007)$ but not significantly in females $(r=0.02, P=0.91)$.

First breeding experiment

Early egg mortality was on average $28.2 \%( \pm 2.6)$ and not significantly different in scale from late mortality $(30.9 \% \pm 4.2)$ (paired $t$-test, $t=0.64$, d.f. $=39, P=0.53)$. The two mortalities were not significantly correlated $(r$ $=0.29, n=40, P=0.07)$. Early mortality was mainly explained by male $\times$ female interaction effects. Late offspring mortality was significantly explained by male and 


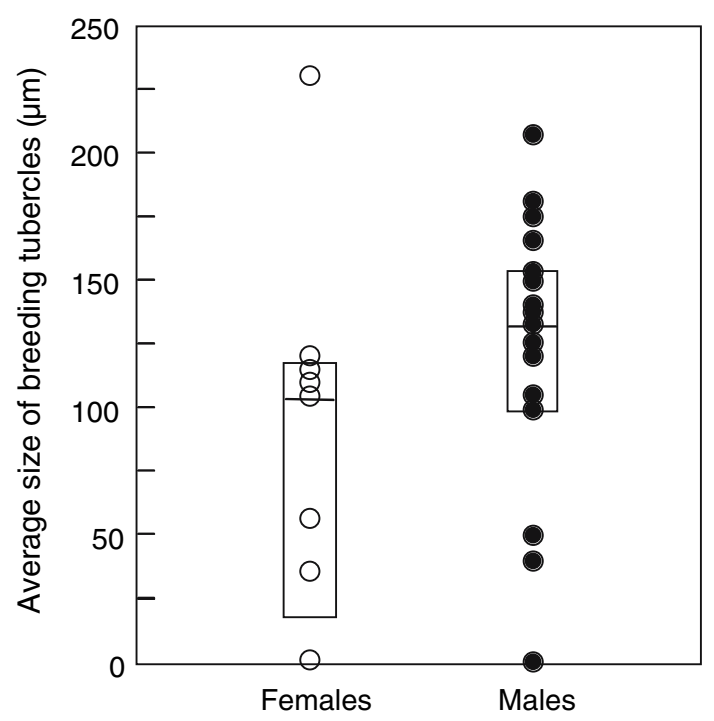

Fig. 1 Average size of breeding tubercles of mature females and males caught at the beginning of the spawning season. The boxes give the medians and quartiles. See text for statistics

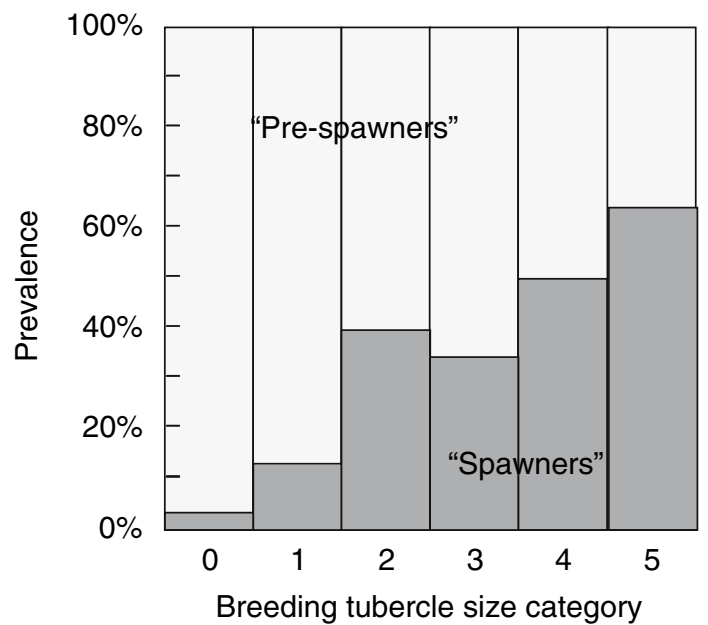

Fig. 2 First sample: the frequencies of "pre-spawners" and "spawners" in the six categories of breeding tubercle size (males and females pooled, see text for separate analyses)

female main effects but not by the male $\times$ female interaction (Table 1). Table 1 also gives the variance component estimates for the sire and dam effects on offspring survival.

Mean early offspring mortality was not linked to any male characteristics, including the size of the breeding tubercles $(|r|<0.31, P$ always $>0.3)$. This corresponds to the finding of no significant sire effects on early mortality (Table 1). However, the sire effect on late offspring mortality reveals significant variation in genetic quality (Table 1). It turned out that this variation was again not significantly linked to the size of the breeding tubercles
(Fig. 3A), although omitting one extreme value would reveal a significant correlation between tubercle size and mean offspring survival (Fig. 3A). Tubercle size was negatively correlated to the range of possible late mortalities per male (Fig. 3B).

Second sample and second breeding experiment

The 8 male and 8 female spawners that were caught around the peak of the breeding season were not significantly different in size or age to the mature males or females, respectively, that were caught at the beginning of the spawning season $(|t|<1.5$, p always $>0.15)$. The same was true for the size of the breeding tubercles of the mature males $\left(N_{\text {total }}=27\right)$ and females $\left(N_{\text {total }}=17 ;|t|<0.5, P\right.$ always $>0.63)$. In this second sample, the size of breeding tubercles was again not significantly linked to fish size (within each sex: $|r|<1.6, P$ always $>0.70$ ) or age $\left(F_{1,14}=0.04, P=0.84\right)$.

Early egg mortality was on average $15.2 \%( \pm 0.9)$ and not significantly different in scale from late mortality $(14.8 \% \pm 1.2)$ (paired $t$-test, $t=0.35$, d.f. $=111, P=0.73)$. Unlike in the first breeding experiment, the two mortalities were significantly correlated $(r=0.43, n=112, P<0.0001)$. Both mortalities were explained by male, female, and male $\times$ female interaction effects (Table 1). Table 1 also gives the variance component estimates for the various effects on offspring survival. Although these analyses on embryo mortality reveal again significant variation in male genetic quality, mean early or late offspring mortality was not significantly linked to any male characteristics, including tubercle size ( $|r|<0.33, P$ always $>0.4$; see also Fig. 3C, D).

\section{Explaining embryo mortality}

The statistical models in Table 1 each explain a large fraction of the total variance in early and late embryo mortality. Dam effects include genetic and environmental effects, and maternal genetic effects. Significant sire effects directly reveal variation in genetic quality. Assuming that epistatic genetic variance is of negligible importance, the additive genetic variance can be calculated as four times the sire component of variance (Lynch and Walsh 1998; Neff and Pitcher 2005). To give an example: for the early embryo mortality in the second breeding experiment, the additive genetic variance explains about $61.7 \%(4 \times 0.00199 / 0.0129$, see Table 1$)$ of the total phenotypic variance in mortality under the assumption of negligible epistatic genetic variance. The dam $\times$ sire effect can be used to estimate the non-additive genetic variance which is, in the same example, 0.00992 (four times the dam $\times$ sire component of variance) and represents $76.9 \%$ of the total phenotypic variance in early 
Table 1 Variance component analyses on two consecutively determined embryo mortalities during the first month of development

\begin{tabular}{|c|c|c|c|c|c|c|c|c|c|c|}
\hline & \multicolumn{5}{|c|}{ Early mortality (first 2 weeks) } & \multicolumn{5}{|c|}{ Late mortality (second 2 weeks) } \\
\hline & SS & d.f. & $F$ & $P$ & $\sigma^{@}(\%$ of total $)$ & SS & d.f. & $F$ & $P$ & $\sigma^{@}(\%$ of total $)$ \\
\hline \multicolumn{11}{|c|}{ First breeding experiment: } \\
\hline Dam & 0.02 & 1 & 0.2 & 0.65 & $2.53 \times 10^{-5}(0.1 \%)$ & 0.8 & 1 & 25.8 & 0.0007 & $39.1 \times 10^{-3}(38.6 \%)$ \\
\hline Sire & 0.3 & 9 & 0.4 & 0.92 & $1.3 \times 10^{-6}(0.0 \%)$ & 1.6 & 9 & 5.6 & 0.009 & $36.0 \times 10^{-3}(35.6 \%)$ \\
\hline Dam $\times$ sire & 0.7 & 9 & 21.0 & $<0.0001$ & $2.29 \times 10^{-2}(83.9 \%)$ & 0.3 & 9 & 1.5 & 0.20 & $5.46 \times 10^{-3}(5.4 \%)$ \\
\hline Residual & & & & & $4.35 \times 10^{-3}(16.0 \%)$ & & & & & $20.6 \times 10^{-3}(20.4 \%)$ \\
\hline \multicolumn{11}{|c|}{ Second breeding experiment: } \\
\hline Dam & 0.7 & 6 & 18.3 & $<0.0001$ & $6.96 \times 10^{-3}(54.0 \%)$ & 0.23 & 6 & 26.5 & $<0.001$ & $16.49 \times 10^{-3}(67.6 \%)$ \\
\hline Sire & 0.2 & 7 & 5.3 & 0.0002 & $1.99 \times 10^{-3}(15.4 \%)$ & 1.65 & 7 & 3.2 & 0.008 & $1.63 \times 10^{-3}(6.7 \%)$ \\
\hline Dam $\times$ sire & 0.3 & 42 & 4.4 & $<0.0001$ & $2.48 \times 10^{-3}(19.2 \%)$ & 0.43 & 42 & 4.7 & $<0.001$ & $4.08 \times 10^{-3}(16.7 \%)$ \\
\hline Residual & & & & & $1.47 \times 10^{-3}(11.4 \%)$ & & & & & $2.18 \times 10-3(9.0 \%)$ \\
\hline
\end{tabular}

The table gives the outcome of two breeding experiments, one at the start of the spawning season ( 2 females $\times 10$ males) and the second around the peak of the season ( 7 females $\times 8$ males). Because both experimental set-ups were fully balanced, results based on REML (Restricted Maximum Likelihood) and EMS (Expected Mean Square) methods were very similar, except for early mortality in the first breeding experiment for which the strong interaction effect caused variance components estimates of dam and sire effects to be negative when based on the EMS algorithm. Thus for this case REML-based estimates are presented. Dam and sire and dam $\times$ sire interaction were random effects in the model

Fig. 3 Average size of breeding tubercles in males versus characteristics of late offspring mortality. First breeding experiment: breeding tubercles versus (A) average late offspring mortality $(r=$ $-0.02, P=0.96$, filled regression line; if the extreme male $(*)$ were excluded: $r=$ $-0.69, P=0.04$, hatched regression line), and (B) the range of recorded late offspring mortalities per male according to which female it is crossed with $(r=-0.81, P=0.004)$. Second experiment: breeding tubercles versus $(\mathbf{C})$ average late offspring mortality $(r=$ $-0.16, P=0.70)$, and (D) the range of recorded late offspring mortalities per male according to which female it is crossed with $(r=0.17, P=0.69)$
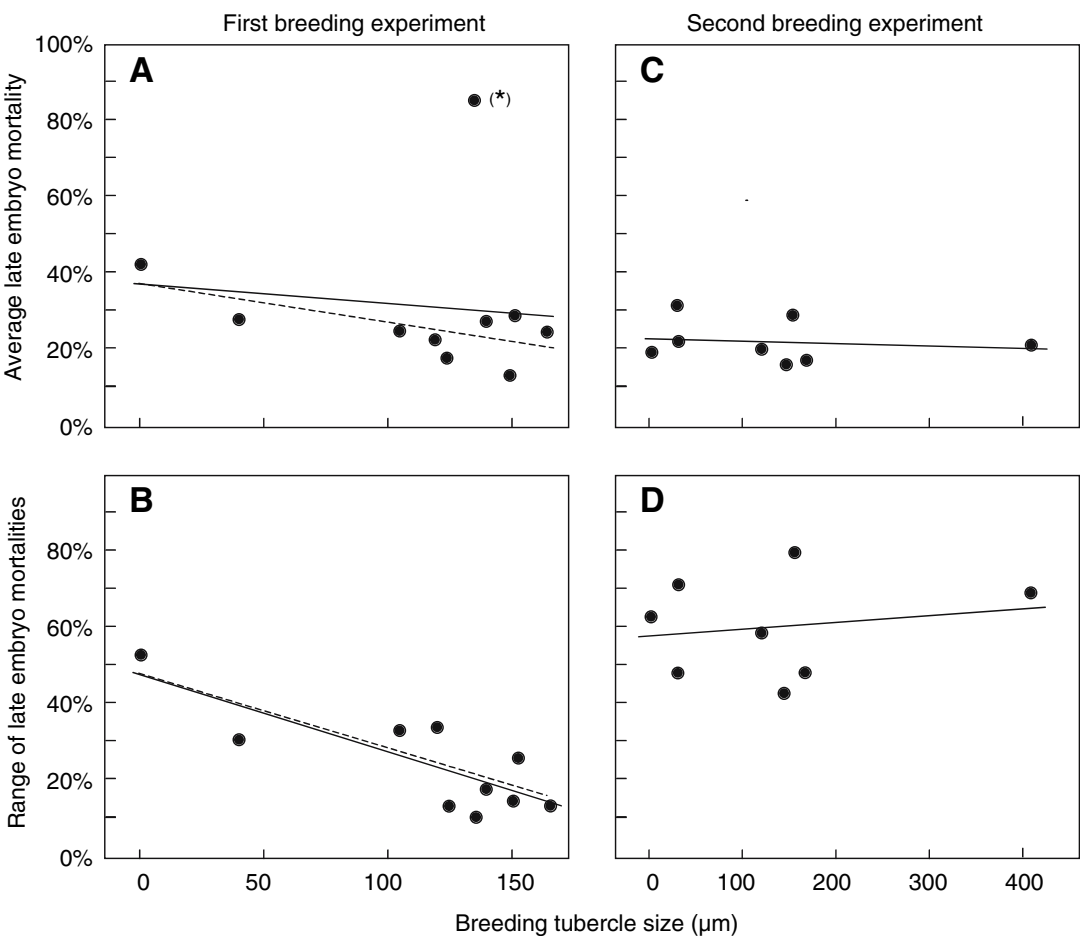

mortality. The difference between the dam and sire component of variance can be used to estimate the total maternal effect variance which is 0.00497 or $38.5 \%$ of the phenotypic variance in early mortality during the second experiment. Table 2 gives, for both breeding experiments, the percentages of the total variance in early and late embryo mortality that may be explained by additive genetic variance, non-additive genetic variance, and maternal effects variance - assuming that epistatic genetic variance is of negligible importance. However, since in all cases the total percentage adds up to $>100 \%$, epistatic genetic variance appears to play an important role in determining embryo mortality (Lynch and Walsh 1998; Neff and Pitcher 2005). 
Table 2 Percentage of the total variance in early and late embryo mortality that is explained by additive genetic variance, non-additive genetic variance, and environmental maternal effects variance

1st experiment 2nd experiment

(\%)

(\%)

Early mortality (first 2 weeks)
Additive genetic variance

Non-additive genetic variance

Maternal effects variance

$<0.1$

$>100$

$<0.1$

61.7

76.9

38.5

Late mortality (second 2 weeks)

Additive genetic variance

$>100$

26.7

Non-additive genetic variance

5.4

66.9

Maternal effects variance

3.1

61.0
The percentages are calculated for each experiment separately, assuming no epistatic genetic variance (Lynch and Walsh 1998; Neff and Pitcher 2005). The sum of the percentages exceeds $100 \%$ in all four blocks of analyses, indicating that epistatic genetic variance is an important aspect of embryo mortality. See text for details on the calculation

\section{Discussion}

It is typical for many salmonids that males are first at the spawning ground and females arrive later (Esteve 2005). Accordingly, we found a higher percentage of mature males than mature females in our first sample that was taken at the beginning of the spawning season. We also found that the size of breeding tubercles is significantly linked to the stage of maturation, even if we only studied fish caught at the spawning ground. If we combine these two findings, we can predict that even if there were no sexual dimorphism in the breeding tubercles of mature individuals, females that are caught during the spawning season may still have smaller breeding tubercles simply because they mature on average later than males. However, when we correct for this potentially confounding effect, we nevertheless find that females have on average smaller breeding tubercles than males. Hence, there is a sexual dimorphism in the secondary sexual characteristics of whitefish -but it is clearly not as obvious as in most other species. Such a sexual dimorphism may potentially have various explanations. In the context of sexual selection and Bateman's principle, it seems plausible that breeding tubercles may at least party function as attractiveness traits and/or that they are somehow linked to intra-sexual dominance.

In our breeding experiments we distinguished between early and late embryo mortality. Our measure of early embryo mortality could potentially include some eggs that remained unfertilized but were counted as dead. At the very early stages of embryo development, unfertilized eggs are hard to distinguish from fertilized eggs. However, for our in vitro fertilization we used sperm-to-egg ratios that were clearly above the critical value below which sperm density is known to be constraining. And if polyspermy would be a problem at high sperm:egg ratios (Franke et al. 2002), we would expect strong sire effects on early mortality in our two-way ANOVAs. In the first experiment, we recorded nearly no sire effect on early mortality, and the analogous sire effect in the second experiment was in about the range of the observed sire effects on late mortality. We therefore believe that our estimates of early embryo mortality are not, or not significantly, confounded by nonfertilized eggs or problems of polyspermy.

The breeding experiments revealed significant dam, sire, and dam $\times$ sire interaction effects on at least some aspects of embryo mortality. Significant dam $\times$ sire effects reveal variation in genetic compatibility, i.e., some male haplotypes fit better to a given female haplotype than others (Neff and Pitcher 2005; Nordeide 2007). Significant sire effects in a species with external fertilization and no paternal care (as is the case here) directly reveal variation in genetic quality. In the first experiment, we found significant sire effects on late embryo mortality only. Here, the range of possible late mortalities was significantly linked to the size of breeding tubercles, i.e., males with larger breeding tubercles were more predictable with respect to offspring survival, and the survival of their offspring tended to be better than that of males with smaller breeding tubercles. This finding is in agreement to previous results on a large-type whitefish species from another Swiss lake (Wedekind et al. 2001a). However, it turned out that the average late embryo mortality of one male (marked in Fig. 3A) had a disproportionally large effect on several analyses of this breeding experiment. The quantitative values in Table 1 should therefore be taken as first estimates only (see also discussion below).

Our second experiment that was done around the peak of the spawning season did not reveal any significant link between the size of the breeding tubercles and early or late offspring survival. This apparent inconsistency to the first experiment indicates that breeding tubercles cannot generally be seen as indicator of good genetic quality, either because (i) they have a condition-dependent expression that is influenced not only by genetic quality but also by environmental factors which weaken the link between quality indicator and offspring viability (Cotton et al. 2004), or (ii) individuals differ in their signaling strategies according to their life-histories (Proulx et al. 2002; Badyaev and Duckworth 2003), or because some environmental conditions do not reveal genetic quality in embryos.

We studied parental effects on offspring survival in the laboratory, i.e., under semi-natural conditions that allow for some standardization and for some control over what 
causes embryo mortality, but we did not work under sterile conditions. Consequently, signs of bacterial, fungal, or oomycete infections that would be expected in the wild were also visible in our experiment. It is still unclear how the natural conditions compare to the conditions in our laboratory. Hence, the quantitative estimates we can offer so far need to be interpreted with some care.

We estimated the percentage of variance in early and late embryo mortality that is explained by additive genetic variance, non-additive genetic variance, and maternal effects variance. For these calculations we used standard quantitative genetics techniques (Lynch and Walsh 1998; Neff and Pitcher 2005) that assume that epistatic genetic variance can be neglected. Epistatic genetic variance cannot be quantified in the North Carolina II design, even if this breeding design is considered one of the most powerful method in quantitative genetics (Lynch and Walsh 1998; Neff and Pitcher 2005).

When we partitioned the variance components in the two experiments, we found striking differences in the outcome. In the first experiment, nearly all the early embryo mortality was explained by non-additive genetic effects, while nearly all the late embryo mortality seemed to be due to additive genetic effects. In the second experiment, additive genetic effects, non-additive genetic effects, and maternal effects variance all seemed to play an important role in determining early or late embryo mortality. Such different outcomes may be due to natural differences that are somehow linked to the course of the spawning season (the first experiment was done at the start of the breeding season, the other one around its peak). However, in the first breeding experiment we had put a higher priority on studying sire effects and hence used only two females that were mated with 10 males. Therefore, dam and dam $\times$ sire effects could be strongly influenced by chance events. Such chance events are likely to influence the estimates of the variance components that include dam effects. However, the estimates of the sire effects based on 10 males in the first breeding experiment are expected to be more robust. The same is expected for sire and dam effects that are calculated from the $7 \times 8$ breeding design of the second experiment.

Epistasis is common for complex traits like embyo survival (Carlborg and Haley 2004; Kroymann and MitchellOlds 2005). Our calculations of the variance components revealed that epistatic genetic variance must be an important aspect of early and late embryo mortality, because the sum of all percentages always exceeded $100 \%$. The findings of previous studies that used comparable experimental approaches lead to the same conclusion (Wedekind et al. 2001a; Neff and Pitcher 2005; Rudolfsen et al. 2005), and a recent study on Chinook salmon (Oncorhynchus tshawytscha) found that additive genetic, non-additive genetic, and maternal effects variance accounted for $56 \%, 54 \%$, and $51 \%$ of the total variance in embryo survivorship (Pitcher and Neff 2006a). Hence, a North Carolina II breeding design with in vitro fertilization and large family sizes can only provide maximal estimates of the additive genetic variance, non-additive genetic variance, and maternal effects variance, i.e., the quantities are likely to be overestimated except for the maternal effects variance because the epistatic effects are removed from the latter by the substraction $V_{\mathrm{d}}-V_{\mathrm{s}}$, see equation 20.4a and 20.4b in Lynch and Walsh (1998). Nevertheless, the scale of our estimates still suggests that additive genetic effects, non-additive genetic effects, and maternal effects variance can be important.

The general view on the heritability of fitness is that it is typically below 10\% (Burt 1995; Kruuk et al. 2000; Qvarnstrom et al. 2006), and studies mainly on birds and mammals suggest that fitness benefits from mate selection for good genes are weak (Møller and Alatalo 1999; Qvarnstrom et al. 2006). The present and some recent studies on external fertilizers with no parental care (some frogs and fish) suggest that heritability of fitness and the potential fitness gain of good-genes sexual selection may both be significantly higher (Welch et al. 1998; Wedekind et al. 2001a; Pitcher and Neff 2006a).

The kind of quantitative analyses we used here cannot explain the detailed nature of the genetic effects. Significant genetic effects on embryo survival could be due, for example, to variation in the general mutational load in the genome and/or to allelic variation on some key loci. Wedekind et al. (2004) used several within-family comparisons to test MHC effects on embryo survival and found a significant link between embryo susceptibility to a bacterial infection by Pseudomonas fluorescens and the allelic specificity on the MHC (major histocompatibility complex). Because the MHC plays a key role in immune recognition, the finding demonstrates that the immune system of fish embryos is, from a certain point on, active and influences embryo survival even before hatching. This finding was recently supported in analyses on Chinook salmon (Pitcher and Neff, 2006a, b). It is, however, still unclear at which developmental stage the immune system starts to be functional.

Male whitefish have large gonads that reach up to $5 \%$ of total body weight (Rudolfsen et al. submitted; this study), and a fertilization event usually takes only few moments in group spawners (Wedekind 1996). Therefore, female whitefish do not seem to be constrained in any way from getting their eggs fertilized, and there seems to be not much reason to assume that males should be choosy. Nevertheless, in all coregonids of the Alpine region, females have large breeding tubercles (some even in the range of the largest ones found in males). This fact suggests that breeding tubercles do not just signal genetic quality but 
may also serve, for example, as contact organ to ensure close contact between the sexes during mating. Mating of many Alpine whitefish including $C$. zugensis usually takes place in deep water (below $20 \mathrm{~m}$ ) and has not been studied much yet. It is therefore still unclear why female whitefish may need breeding tubercles as contact organs, while females of many cyprinids do not.

Another largely unsolved problem in a communication system that is based on breeding tubercles is the following: 'good-genes' models of sexual selection usually assume secondary sexual traits to be expensive to build and/or maintain in order to act as quality signal (the "handicap principle", see, for example, Zahavi (1975) and Grafen (1990)). Breeding tubercles are small and built of apparently inexpensive material (Wiley and Collette, 1970). They are therefore not obviously handicapping, and although the variation in the size of breeding tubercles can be large, it is not obvious why only high-quality individuals should be able to afford a large signal as expected from the handicap principle. One possibility is that breeding tubercles are amplifiers of another trait, for example fluctuating asymmetry (Hasson 1991). Alternative ideas that allow for non-handicapping signals have been developed (Wedekind 1994; Viljugrein 1997), but they seem to be more suitable for pair-bonding species or for characteristics that consists of multiple traits and can potentially contain much specific information (like, for example, MHC-linked odours). It is unclear whether these alternative models can be applied to whitefish and to a signaling system that is based on breeding tubercles. Nevertheless, we found in one of two experiments that the size of males' breeding tubercles reveal important aspects of their genetic quality, i.e., under some conditions, breeding tubercles can be used to predict some of the additive genetic variance in offspring survival that we found.

Acknowledgments We thank N. Hofer, A. Hofer, and J. Muggli for catching the fish, A. Steffen and U. Lauterburg for technical assistance, and T. Pitcher and the anonymous reviewers for helpful comments on an earlier version of this paper. The study was funded by the Swiss National Science Foundation.

\section{References}

Amundsen T (2000) Why are female birds ornamented? Trends Ecol Evol 15:149-155

Andersson M (1994) Sexual selection. Princeton University Press, Princeton

Badyaev AV, Duckworth RA (2003) Context-dependent sexual advertisement: plasticity in development of sexual ornamentation throughout the lifetime of a passerine bird. J Evol Biol 16:1065-1076

Bang A, Gronkjaer P, Clemmesen C et al (2006) Parental effects on early life history traits of Atlantic herring (Clupea harengus L.) larvae. J Exp Mar Biol Ecol 334:51-63
Brown JL (1997) A theory of mate choice based on heterozygosity. Behav Ecol 8:60-65

Burt A (1995) Perspective-the evolution of fitness. Evolution 49:1-8

Carlborg O, Haley CS (2004) Epistasis: too often neglected in complex trait studies? Nat Rev Genet 5:618-625

Ciereszko A, Dabrowski K (1993) Estimation of sperm concentration of Rainbow trout, whitefish and Yellow Perch using a spectrophotometric technique. Aquaculture 109:367-373

Cotton S, Fowler K, Pomiankowski A (2004) Do sexual ornaments demonstrate heightened condition-dependent expression as predicted by the handicap hypothesis? Proc R Soc Lond B 271: $771-783$

Dickerson BR, Brinck KW, Willson MF et al (2005) Relative importance of salmon body size and arrival time at breeding grounds to reproductive success. Ecology 86:347-352

Esteve M (2005) Observations of spawning behaviour in Salmoninae: Salmo, Oncorhynchus and Salvelinus. Rev Fish Biol Fish 15: $1-21$

FAO (1965) Manual of sampling and statistical methods for fisheries biology. FAO Manuals Fisher Sci 1(Fasc. 9, Sec. 4):37-40

Fleming IA (1998) Pattern and variability in the breeding system of Atlantic salmon (Salmo salar), with comparisons to other salmonids. Can J Fish Aquat Sci 55:59-76

Fleming IA, Gross MR (1994) Breeding competition in a pacific salmon (coho, Oncorhynchus kisutch) - measures of natural and sexual selection. Evolution 48:637-657

Franke ES, Babcock RC, Styan CA (2002) Sexual conflict and polyspermy under sperm-limited conditions: In situ evidence from field simulations with the free-spawning marine echinoid Evechinus chloroticus. Am Nat 160:485-496

Garant D, Dodson JJ, Bernatchez L (2001) A genetic evaluation of mating system and determinants of individual reproductive success in Atlantic salmon (Salmo salar L.). J Hered 92:137-145

Garant D, Dodson JJ, Bernatchez L (2003) Differential reproductive success and heritability of alternative reproductive tactics in wild Atlantic salmon (Salmo salar L.). Evolution 57:1133-1141

Gilbert L, Williamson KA, Hazon N et al (2006) Maternal effects due to male attractiveness affect offspring development in the zebra finch. Proc R Soc Lond B 273:1765-1771

Grafen A (1990) Biological signals as handicaps. J Theor Biol 144:517-546

Hamilton WD, Zuk M (1982) Heritable true fitness and bright birds - a role for parasites. Science 218:384-387

Hasson O (1991) Sexual displays as amplifiers - practical examples with an emphasis on feather decorations. Behav Ecol 2:189-197

Hill GE (1991) Plumage coloration is a sexually selected indicator of male quality. Nature 350:337-339

Iyengar VK, Eisner T (1999) Female choice increases offspring fitness in an arctiid moth (Utetheisa ornatrix). Proc Natl Acad Sci USA 96:15013-15016

Jacob A, Nusslé S, Britschgi A et al (submitted) Male dominance linked to size and age, but not to genetic quality in brown trout (Salmo trutta)

Johnsen A, Delhey K, Schlicht E et al (2005) Male sexual attractiveness and parental effort in blue tits: a test of the differential allocation hypothesis. Anim Behav 70:877-888

Kortet R, Taskinen J (2004) Parasitism, condition and number of front head breeding tubercles in roach (Rutilus rutilus L.). Ecol Freshw Fish 13:119-124

Kortet R, Vainikka A, Rantala MJ et al (2003) Sexual ornamentation, androgens and papillomatosis in male roach (Rutilus rutilus). Evol Ecol Res 5:411-419

Kortet R, Vainikka A, Rantala MJ et al (2004a) In vitro embryo survival and early viability of larvae in relation to male sexual ornaments and parasite resistance in roach, Rutilus rutilus L. J Evol Biol 17:1337-1344 
Kortet R, Vainikka A, Rantala MJ et al (2004b) Sperm quality, secondary sexual characters and parasitism in roach (Rutilus rutilus L.). Biol J Linn Soc 81:111-117

Kroymann J, Mitchell-Olds T (2005) Epistasis and balanced polymorphism influencing complex trait variation. Nature 435:95-98

Kruuk LEB, Clutton-Brock TH, Slate J et al (2000) Heritability of fitness in a wild mammal population. Proc Natl Acad Sci USA 97:698-703

Largiadèr CR, Estoup A, Lecerf F et al (2001) Microsatellite analysis of polyandry and spawning site competition in Brown trout (Salmo trutta L.). Genet Select Evol 33:S205-S222

Lynch M, Walsh B (1998) Genetics and analysis of quantitative traits. Sinauer Associates Inc, Sunderland, Massachusetts

Milinski M, Bakker TCM (1990) Female sticklebacks use male coloration in mate choice and hence avoid parasitized males. Nature 344:330-333

Møller AP, Alatalo RV (1999) Good-genes effects in sexual selection. Proc R Soc Lond B 266:85-91

Müller G, Ward PI (1995) Parasitism and heterozygosity influence the secondary sexual characters of the European minnow, Phoxinus phoxinus (L) (Cyprinidae). Ethology 100:309-319

Neff BD, Pitcher TE (2005) Genetic quality and sexual selection: an integrated framework for good genes and compatible genes. Molec Ecol 14:19-38

Nordeide JT (2007) Is there more in 'gamete quality' than quality of the gametes? A review of effects of female mate choice and genetic compatibility on offspring quality. Aquacult Res 38:1-16

Ottova E, Simkova A, Jurajda P et al (2005) Sexual ornamentation and parasite infection in males of common bream (Abramis brama): a reflection of immunocompetence status or simple cost of reproduction? Evol Ecol Res 7:581-593

Petrie M, Williams A (1993) Peahens lay more eggs for peacocks with larger trains. Proc R Soc Lond B 251:127-131

Pitcher TE, Neff BD (2006a) Genetic quality and offspring performance in Chinook salmon: implications for supportive breeding. Conserv Genet 8:607-616

Pitcher TE, Neff BD (2006b) MHC class IIB alleles contribute to both additive and nonadditive genetic effects on survival in Chinook salmon. Molec Ecol 15:2357-2365

Proulx SR, Day T, Rowe L (2002) Older males signal more reliably. Proc R Soc Lond B 269:2291-2299

Quinn TP, Foote CJ (1994) The effects of body size and sexual dimorphism on the reproductive behavior of Sockeye salmon, Oncorhynchus nerka. Anim Behav 48:751-761

Qvarnstrom A, Brommer JE, Gustafsson L (2006) Testing the genetics underlying the co-evolution of mate choice and ornament in the wild. Nature 441:84-86

Qvarnstrom A, Forsgren E (1998) Should females prefer dominant males? Trends Ecol Evol 13:498-501

Rinchard J, Dabrowski K, Van Tassell JJ et al (2005) Walleye (Sander vitreum) fertilization success is influenced by gamete storage and sperm:egg ratio. J Fish Biol 67:1157-1161

Rudolfsen G, Figenschou L, Folstad I et al (2005) Potential fitness benefits from mate selection in the Atlantic cod (Gadus morhua). J Evol Biol 18:172-179
Rudolfsen G, Müller R, Urbach D et al (in press) Predicting the mating system from phenotypic correlations between life-history and sperm quality traits in the Alpine whitefish Coregonus zugensis. Behav Ecol Sociobiol

Taskinen J, Kortet R (2002) Dead and alive parasites: sexual ornaments signal resistance in the male fish, Rutilus rutilus. Evol Ecol Res 4:919-929

Urbach D, Bittner D, Lenz TL et al (in press) Sperm velocity in an Alpine whitefish: effects of age, size, condition, fluctuating asymmetry, and gonad abnormalities. J Fish Biol

Viljugrein H (1997) The cost of dishonesty. Proc R Soc Lond B 264:815-821

Wedekind C (1992) Detailed information about parasites revealed by sexual ornamentation. Proc R Soc Lond B 247:169-174

Wedekind C (1994) Handicaps not obligatory in sexual selection for resistance genes. J Theor Biol 170:57-62

Wedekind C (1996) Lek-like spawning behaviour and different female mate preferences in roach (Rutilus rutilus). Behaviour 133:681-695

Wedekind C (2002) Sexual selection and life-history decisions: implications for supportive breeding and the management of captive populations. Conserv Biol 16:1204-1211

Wedekind C, Müller R (2004) Parental characteristics versus egg survival: towards an improved genetic management in the supportive breeding of lake whitefish. Ann Zool Fenn 41: $105-115$

Wedekind C, Müller R, Spicher H (2001a) Potential genetic benefits of mate selection in whitefish. J Evol Biol 14:980-986

Wedekind C, Müller R, Steffen A et al (2001b) A low-cost method of rearing multiple batches of fish. Aquaculture 192:31-37

Wedekind C, Rudolfsen G, Jacob A et al (2007) The genetic consequences of hatchery-induced sperm competition in a salmonid. Biol Conserv 137:180-188

Wedekind C, Strahm D, Schärer L (1998) Evidence for strategic egg production in a hermaphroditic cestode. Parasitology 117: 373-382

Wedekind C, Walker M, Portmann J et al (2004) MHC-linked susceptibility to a bacterial infection, but no MHC-linked cryptic female choice in whitefish. J Evol Biol 17:11-18

Weir LK, Hutchings JA, Fleming IA et al (2004) Dominance relationships and behavioural correlates of individual spawning success in farmed and wild male Atlantic salmon, Salmo salar. J Anim Ecol 73:1069-1079

Welch AM (2003) Genetic benefits of a female mating preference in gray tree frogs are context-dependent. Evolution 57: 883-893

Welch AM, Semlitsch RD, Gerhardt HC (1998) Call duration as an indicator of genetic quality in male gray tree frogs. Science 280:1928-1930

Wiley ML, Collette BB (1970) Breeding tubercles and contact organs in fishes: their occurance, structure, and significance. Bull Am Mus Nat Hist 143:145-216

Zahavi A (1975) Mate selection - a selection for a handicap. J Theor Biol 53:205-214 